\title{
The Development and Psychometric Properties of the «Self-Regulated Knowledge Scale - University» (SRKS-U)
}

\section{Sara Manganelli ${ }^{1,2}$ - Fabio Alivernini ${ }^{2}$ - Luca Mallia ${ }^{1,3}$ Valeria Biasi ${ }^{1}$}

${ }^{1}$ Università degli Studi Roma Tre - Department of Education (Italy)

${ }^{2}$ National Institute for the Educational Evaluation of Instruction and Training Istituto Nazionale per la Valutazione del Sistema Educativo di Istruzione e Formazione (INVALSI) (Italy)

${ }^{3}$ Università degli Studi di Roma Foro Italico - Department of Department of Movement, Human and Health Sciences (Italy)

doi: 10.7358/ecps-2015-012-mang sara.manganelli@gmail.com fabio.alivernini@invalsi.it luca.mallia@uniroma4.it valeria.biasci@uniroma3.it

\author{
SVILUPPO E PROPRIETÀ PSICOMETRICHE \\ DELLA «SCALA DI AUTO-REGOLAZIONE \\ DEGLI APPRENDIMENTI - UNIVERSITÀ» (SARA-U)
}

\section{Abstract}

Cognitive self-regulation refers to the mental processes that students adopt with the aim of adapting and changing their processes of cognition and that can lead to positive results in terms of learning. The purpose of the present study was to develop a short scale with sound psychometric properties in order to measure self-regulated knowledge in university students. The scale was designed on the basis of the Self-Regulated Learning theoretical framework (Pintrich, 2004) as well as the results of previous studies investigating students' cognitive self-regulation. The "Self-Regulated Knowledge Scale - University" (SRKS-U) was made up of five subscales, each one intended to measure one of the following cognitive processes: 
knowledge networking, knowledge extraction, knowledge practice, knowledge critique, and knowledge monitoring. The psychometric properties of the scale were tested on a sample of 2.209 Italian university students (average age $=22.6$ years; $S D=6.14 ; 67 \%$ female) to ascertain its reliability (internal consistency) and factorial structure (using a Confirmatory Factor Analysis). A multigroup analysis was employed to verify the measurement invariance of SRKS-U across gender. The results proved the good internal consistency of the scale, confirmed its theoretical structure, and demonstrated its configural, metric and scalar invariance across gender. Given its brevity and its good psychometric properties, the SRKS-U can be usefully employed in research programs which aim to investigate self-regulated knowledge as well as in evaluation programs as a screening instrument to provide information that can be used for developing targeted interventions in order to enhance students'self-regulation of learning.

Keywords: Cognitive strategies, Key competencies, Learning to learn, Self-Regualted Learning, Validity.

\section{INTRODUCTION AND AIM OF THIS EMPIRICAL STUDY}

Cognitive self-regulation refers to the mental activities and processes that students adopt with the aim of adapting and changing their processes of cognition and that can lead to positive results in terms of learning, with the acquisition of knowledge, understanding and skills (Pintrich, 2004). It involves the selection and use of various cognitive strategies for organizing, elaborating and memorizing information as well as the self-monitoring of the process of acquisition of knowledge in order to control its progress and fill in any gaps they may have (Vermunt, 1998).

Several studies have shown that self-regulation of knowledge and the use of cognitive activities positively influence students' academic achievement and performance (e.g., Richardson, Abraham, \& Bond, 2012) and tend to prevent academic drop-out (De Marco \& Albanese, 2009). Thanks to self-regulation of learning students can actively build up internal representations of their knowledge and can monitor and regulate certain aspects of their cognition. The approach to learning they choose can affect the quality of and outcome of study (Socha \& Sigler, 2014).

Research has shown that deep approaches to learning (in which students actively process the material studied in order to understand it), generally promote high achievement and enhanced performance, while surface approaches to learning (in which students learn information by rote in order to simply reproduce or repeat it) are negatively associated with academic performance (Diseth et al., 2010; Heikkila et al., 2011). 
The extent to which students employ self-regulatory learning strategies may mediate and moderate the effects of factors such as motivation and affect, dispositional characteristics (e.g., intellectual capacity and personality), and psychosocial context on academic performance (Richardson et al., 2012). The acquisition of cognitive abilities and learning to learn skills is an accomplishment that the European Commission has defined as necessary for personal fulfilment and for enhancing the possibility of lifelong learning, and it has been indicated as one of the desired learning outcomes of the study programmes of every European country (La Rocca, Margottini, \& Capobianco, 2014).

Given the benefits for both the knowledge acquisition process and the academic performance and future success of students who engage in cognitive self-regulation, it is essential to have instruments that allow us to reliably assess this competence. They can provide us with valuable information that can increase our knowledge of these processes leading to important practical applications. Studies indicate that the more students understand about how they learn, the more likely they are to become independent, responsible, selfconfident learners (Sizoo, Malhotra, \& Bearson, 2003).

Encouraging students to asses their competency in the acquisition and regulation of their own knowledge can stimulate them to engage in further processes of reasoning and self-evaluation as regards this competency (Pellerey, 1996).

Furthermore, a proper assessment of students' regulation of knowledge can assist teachers in the choice of teaching methods and inform the interventions aimed at improving students' academic performance. In fact, students' approaches to learning are, at least in part, a result of the learning context, teaching methods and the anticipated methods of evaluation (Diseth et al., 2010; Alivernini, Lucidi, \& Manganelli, 2012) and can be improved by means of appropriate training courses (Hofer \& Shirley, 2003).

The purpose of the present study is to develop a short scale with sound psychometric properties in order to measure self-regulated knowledge in university students, which can be easily employed in different contexts (research or evaluation projects, orienting and training programs, etc.). The scale is designed on the basis of the Self-Regulated Learning (SRL) theoretical framework (Pintrich, 2004) as well as the results of previous studies investigating students' cognitive self-regulation. The psychometric properties of the scale are thoroughly tested on a large sample of Italian university students in order to ascertain its factorial structure, internal consistency and measurement invariance.

In the remainder of this paper we first give a brief review of the literature that forms the theoretical background for the development of the scale. We then describe the scale and the methods of the empirical study of its psychometric properties. Finally we present and discuss the results, also 
considering out some of their implications for programs intended to enhance students' academic achievement, as well as for future research.

\section{Self-Regulated KNOWLedge}

There is extensive agreement as regards the fact that learning is an active, constructive and self-directed process in which the learner builds up internal knowledge representations that form a personal interpretation of his or her learning experiences (Vermunt, 1998). However, the research literature on college and university student learning is quite diverse and many different models have been proposed.

The Self-Regulated Learning (SRL) model (Pintrinch, 2004) provides a conceptual framework of college student motivation and regulation that is based on a psychological analysis of academic learning. It is particularly attractive because it includes the most comprehensive set of constructs for assessing learning-related, self-regulatory strategies (Richardson et al., 2012) and it has obtained a fairly wide base of empirical support from both laboratory and field-based studies (e.g., Credé \& Phillips, 2011). The SRL defines four different areas for self-regulated learning: cognition, motivation/affect, behaviour, and context. These four components are clearly distinguished but they interact and are assumed to be important determinants of learning and hence academic performance. Self-regulation of cognition and behaviour can directly affect academic performance, while mediating the influence of motivation, which also affects it (e.g., Alivernini \& Lucidi, 2011), although in a more indirect way (Credé \& Phillips, 2011). Students' perceptions of the learning context influence their regulation of the other components (Alivernini \& Manganelli, 2015): self-regulation of cognition, motivation and behaviour is seen as situation specific and task specific. The SRL model provides a detailed description of each of the four components of self-regulated learning (Pintrich, 2000 and 2004). In the present study we focused on the self-regulation of knowledge and developed the scale with the aim of measuring this component.

Self-regulation of knowledge refers to the cognitive and metacognitive strategies that individuals adopt in order to modify their patterns of thought and achieve their learning goals. Cognitive processing strategies are those thinking activities that are used to process learning contents and that directly lead to learning results in terms of knowledge, understanding, and skills (Vermunt, 1998). These strategies are potentially under the control of the individual, although they may also be used more implicitly without much thought or control (Pintrich, 2004). Research into self-regulated learning has revealed a large number of cognitive activities that university students employ to regulate their 
knowledge and the formulation of a widely approved set of components is still under debate (Entwistle \& McCune, 2004). Nevertheless, strategies of rehearsal, elaboration, organization and critical thinking have long been regarded as core elements of self-regulated knowledge (e.g., Richardson et al., 2012).

The rehearsal strategy generally refers to learning by means of repetition of facts, definitions, concepts and topics, in order to memorize them. This approach has been sometimes associated with «surface learning», which is more concerned with the reproduction of the material than with trying to really understand it (e.g., Biggs, Kember, \& Leung, 2001). Rehearsal has also been described as a strategy for memorizing and revising important information that has been previously selected and elaborated (Pintrich, 1990; Credé \& Phillips, 2011).

The organization strategy refers to the selection and summarizing of key pieces of information during the process of studying or learning (e.g., Richardson et al., 2012). It may include several different approaches and activities, ranging from underling key phrases and taking notes to creating summaries, synthesis and schemes (Weinstein \& Palmer, 2002).

The elaboration strategy refers to the creation of connections between information from multiple sources and then to arrange them into a complete structure (Vermunt, 1998). This kind of activity has been described as making connections between what the student already knows and what he/ she is trying to learn (Dowson \& McInerney, 2004), and it involves bringing together information from different sources (e.g. lectures, readings, etc.), and correlating concepts that regard from different subjects (Pintrich \& Van De Groot, 1990; Credé \& Phillips, 2011).

The critical thinking approach refers to the strategies that involve evaluating and questioning the materials to be learnt (Richardson et al., 2012). This strategy may include several activities, such as critically analysing and discussing the study material, questioning its validity and the conclusions drawn by the authors, as well as forming a personal opinion about the information or topic being studied (Vermunt et al., 1998; Credè \& Phillips, 2011). Organization, elaboration and critical thinking are generally seen as "deep» approaches to learning, which refers to the attempt to truly understand the learning material instead of simply reproducing it, as is the case for surface approaches.

An essential element of the self-regulation of knowledge consists of metacognitive activities and processes of control intended to regulate cognitive processing activities. Many studies and theories have dealt with these aspects of study and learning, providing various different definitions and conceptions (Cornoldi, 1995). In the SRL model metacognitive processes are defined as activities of control, by means of which students can monitor their own mental processes and adjust them when needed (Pintrich, 2000). These monitoring skills enable students to be aware of their progress in the 
process of learning and to understand if there are any gaps in their knowledge, to choose and make proper use of cognitive strategies and to adapt them to their specific study goals and learning environments (Cera, Mancini, $\&$ Antonietti, 2013). Such activities of monitoring of the processes of knowledge acquisition indirectly lead to positive results, by regulating the use of cognitive strategies (Vermunt, 1998). This happens also in different settings for the activities of monitoring of personal attitudes related to the perception of self-efficacy (Biasi et al., 2014). Monitoring and control strategies are especially relevant in the context of higher education, where external support for students is quite limited (Heikkila et al., 2011).

Several questionnaires and inventories have been developed to measure learning processes and study strategies (see Entwistle \& McCune, 2004 for a review). In the context of the SRL theoretical framework, the Motivated Strategies for Learning Questionnaire (MSLQ; Pintrich et al., 1991) is certainly the most widely used instrument. It consists of fifteen subscales that assess students' motivation to study the course material, as well as their learning strategies. The learning strategies subscales are made up of fifty items divided into nine subscales designed to measure three theoretical types of learning strategies: cognitive strategies, metacognitive strategies, and resources management. Although it has been used to study college students in a wide variety of countries, some limitations have been pointed out. For example, Pintrich (2004) noted that the MSLQ was developed ten years before the SRL conceptual model and it therefore does not include all the components of the model. He suggested that it could be used as the basis for new instruments for measuring self-regulated learning in academic contexts. In their meta-analytic review of the MSLQ Credé and Phillips (2011) found that there was extensive support for the structure of the questionnaire but they pointed out the poor formulation of some items and the existence of some psychometric problems.

Another more recent instrument that measures cognitive and metacognitive strategies is the Goal Orientation and Learning Strategies Survey (GOAL-S; Dowson \& McInerney, 2004). It includes four scales measuring rehearsal, elaboration, organization and monitoring strategies and has shown some good psychometric properties. It has also some limitations: it has been tested and validated on high school students rather than university students, it does not include a critical thinking scale and some items have a poor fit with the factorial structure of the scale (Dowson \& McInerney, 2004).

In the Italian context, one of the most commonly used instruments is the Learning Strategy Questionnaire (Pellerey, 1996), which contains a hundred items investigating cognitive and motivational processes and strategies. However, it was developed specifically for high school students and did not include the rehearsal and cognitive thinking scales. 


\section{The «Self-Regulated KnOwledge Scale - University» (SRKS-U)}

The SRKS-U is a self-report questionnaire developed for university students on the basis of the SRL model as well as the results of previous studies investigating students' cognitive self-regulation, which developed and tested the above-mentioned instruments for measuring self-regulation of learning. The scale consisted of five subscales, each of which was intended to measure one of the following cognitive process, that were defined on the basis of the cognitive strategies described above: knowledge extraction, knowledge networking, knowledge practice, knowledge critique, and knowledge monitoring. Each subscale contained three items (making 15 items in total). Students are asked to rate the frequency with which they use the cognitive process or strategy described in each item, using a five points scale $(1=$ «Never»; $2=$ «Seldom»; $3=$ «Sometimes»; $4=$ "Often»; $5=$ "Always or almost always»). The constructs and items of the self-regulated knowledge scale are presented in Table 1 (the Italian version of the SRKS-U is presented in Appendix).

Table 1. Constructs and items of the SRKS-U

(the Italian version of the scale is presented in Appendix).

\begin{tabular}{|c|c|}
\hline Construct & ITEMS \\
\hline & $\begin{array}{l}\text { When you study, how often do you do the following things? } \\
\text { Remember: there are no right or wrong answers, only answers that can } \\
\text { best describe your personal method of study and your situation }\end{array}$ \\
\hline Knowledge extraction & $\begin{array}{l}\text { - I make summaries of the most important things } \\
\text { - I write down the most important concepts of a particular subject } \\
\text { that I study } \\
\text { - I make diagrams or maps of the most important topics }\end{array}$ \\
\hline Knowledge networking & $\begin{array}{l}\text { - I look for similarities or differences between what I'm studying } \\
\text { and what I already know } \\
\text { - I look for connections between the different subjects that I study } \\
\text { - I try to see how what I'm studying is connected with what I already } \\
\text { know }\end{array}$ \\
\hline Knowledge practice & $\begin{array}{l}\text { - I repeat several times the important things to be learnt } \\
\text { - I repeat a topic more than once if I want to learn it well } \\
\text { - I always repeat the most important concepts so as to learn them better }\end{array}$ \\
\hline Knowledge critique & $\begin{array}{l}\text { - I ask myself if I agree with what I read in books or with what is said } \\
\text { in class } \\
\text { - I try to develop my own personal idea about the things that I study } \\
\text { - I try to «do the criticism» or to question what I find on the books }\end{array}$ \\
\hline Knowledge monitoring & $\begin{array}{l}\text { - I check to see if I understand what I'm reading } \\
\text { - I check the elements of a subject I am studying that I still do not know well } \\
\text { - I try to be sure to understand well what I'm studying }\end{array}$ \\
\hline
\end{tabular}


The knowledge extraction subscale investigates the frequency with which the students select the information that they consider most important and give it a structure and meaning. It refers to organizational strategies described in previous studies, but specifically applied to what the students consider to be fundamental knowledge.

The knowledge networking subscale refers to strategies of information elaboration and it investigates the frequency with which students try to link new knowledge with what they already knew and establish connections between different topics.

The knowledge practice subscale investigates the frequency with which students put their knowledge into practice by means of repetition of important information selected from the material being studied. Although it refers to the rehearsal strategy measured in previous questionnaires (e.g., Briggs et al., 2001; Dowson \& McInerney, 2004), it focuses specifically on the repetition of information that has been previously selected, instead of the rehearsal of generic information.

The knowledge critique subscale refers to strategies of critical thinking specifically investigating the frequency with which students question and criticize learning contents in order to form their own personal ideas concerning the topics they are studying.

Finally, the knowledge monitoring subscale refers to metacognitive processes and control strategies focusing on the frequency with which the students monitor the status of their knowledge acquisition process, by checking to see if they have fully understand the study materials and if there are any gaps in their knowledge.

A initial set of 30 items were generated ex novo by two expert researchers on the basis of the research literature and previous questionnaire described above. Then, expert raters and university students conducted a validation process using techniques of thinking aloud in which they evaluated the items in terms of their clarity and relevance to the construct they are intended to measure. The best 15 items were included in the final version of the scale. In the following sections of this paper we will describe the analysis that was conducted in order to verify the psychometric properties of the SRKS-U. Using a sample of Italian university students, the five-factor theoretical structure of the scale was tested by means of Confirmatory Factor Analysis (CFA). The reliability of the scale was then measured in terms of internal consistency. Finally, a series of multigroup analyses were employed in order to verify the measurement invariance of the scale across gender. This is an important aspect because research so far has had some rather mixed results as regards the issue of how gender differences are related to students' regulation of learning (Dowson \& McInerney, 2004). A measure of self-regulated knowledge that is 
equally valid when applied to female and male students is an essential instrument for attaining a better understanding of this issue.

\section{METHOD}

\subsection{Participants and procedure}

The data analysed in the present study came from 2209 Italian freshman students from different faculties of Roma Tre University (67\% females) aged 18-30 years (mean age $=22.6$, age $\mathrm{SD}=6.14$, age skewness $=3.22$, age curtosis $=12.80)$. Most of the students $(80 \%)$ attended a "liceo» before the university, $16 \%$ attended a "technical institute» and $4 \%$ attended vocational education; one third of the students had a job (21\% part-time; $9 \%$ fulltime).

Data came from students who were taking part in a broader online survey promoted by the Psychological Counselling and Orientation Service of Roma Tre University. This survey aimed to analyse the academic experience and psychological distress of first year university students. All students were asked to participate via an e-mail, which described the research and ensured them that they could withdraw from the study at any time, without any kind of penalty associated with the withdrawal. All the participating students provided their informed consent to the survey and filled out an anonymous online questionnaire in February and March 2015.

\subsection{Data analysis}

Data analysis was carried out using the MPlus 7.0 software (Muthen \& Muthen, 1998-2012) and IBM SPSS 22 in four stages. In a preliminary stage, Exploratory Factor Analysis (EFA) was carried out using principal axis extraction and oblimin rotation in order to explore the factorial structure of the SRKS-U. In the second stage of analysis Confirmatory Factor Analyses (CFA) were performed in order to empirically test the postulated five-factor model of the SRKS-U. The model was specified in the following way: (a) each item would have a non-zero loading on the factor that it was designed to measure and a zero loading on each of the other factors; (b) error terms associated with each item would be uncorrelated; (c) each factor would be correlated with all the other factors. The model fit was assessed using 
the chi-squared test statistic and the following fit indices: the Root Mean Square Error of Approximation (RMSEA; Steiger, 1990), the Comparative Fit Index (CFI; Bentler, 1990), and the Standardized Root Mean Square Residual (SRMR; Jöreskog \& Sörbom, 1993). The fit indices results were evaluated following the conventional criteria (Hu \& Bentler, 1999; Schreiber et al., 2006): CFI value close to .95; RMSEA value below .06, and SRMR value below .08. Alternative measurement models were also tested (i.e., a single factor model and a higher order factor model with one second order factor and five first order factors) and their fit was compared to that of the five-factor model.

In the third stage of analysis the internal consistency of each subscale was assessed via Cronbach's alpha. In the fourth stage of analysis, the measurement invariance of the scale across gender was tested in terms of configural, metric and scalar invariance by performing a hierarchical series of multi-group CFAs imposing increasingly restrictive equality constraints on the model's parameters (Vandenberg \& Lance, 2000; Van de Schoot, Lugtig, $\&$ Hox, 2012). Configural invariance was tested by specifying an unrestricted model (Model 1) in which the structure was constrained to be the same across groups, but the parameters were freely estimated. Metric invariance was examined by testing a model in which all of the factor loadings were constrained to be equal across groups (Model 2). Finally, scalar invariance was tested by specifying a model in which both the factor loadings and the intercepts were constrained to be equal across groups (Model 3). Following the recommendations of Cheung and Rensvold (2002), in each step of the analysis the fit of the nested models was compared using two tests: the chi-squared difference test and the change in CFI values (cut-off value: $\Delta \mathrm{CFI} \leq .01$ ).

\section{RESULts}

Table 2 shows bivariate correlations between all the items of SRKS-U, along with the descriptive statistics that form the basis of the item analysis, i.e. the mean, standard deviation, skewness, and curtosis of each item (Barbaranelli \& Natali, 2005). All the correlations were positive and most of them were statistically significant $(p<.05)$. As expected, higher correlations were found between items that were designed to measure the same construct. The descriptive statistics showed that all the items had good psychometric properties (Barbaranelli \& Natali, 2005). 


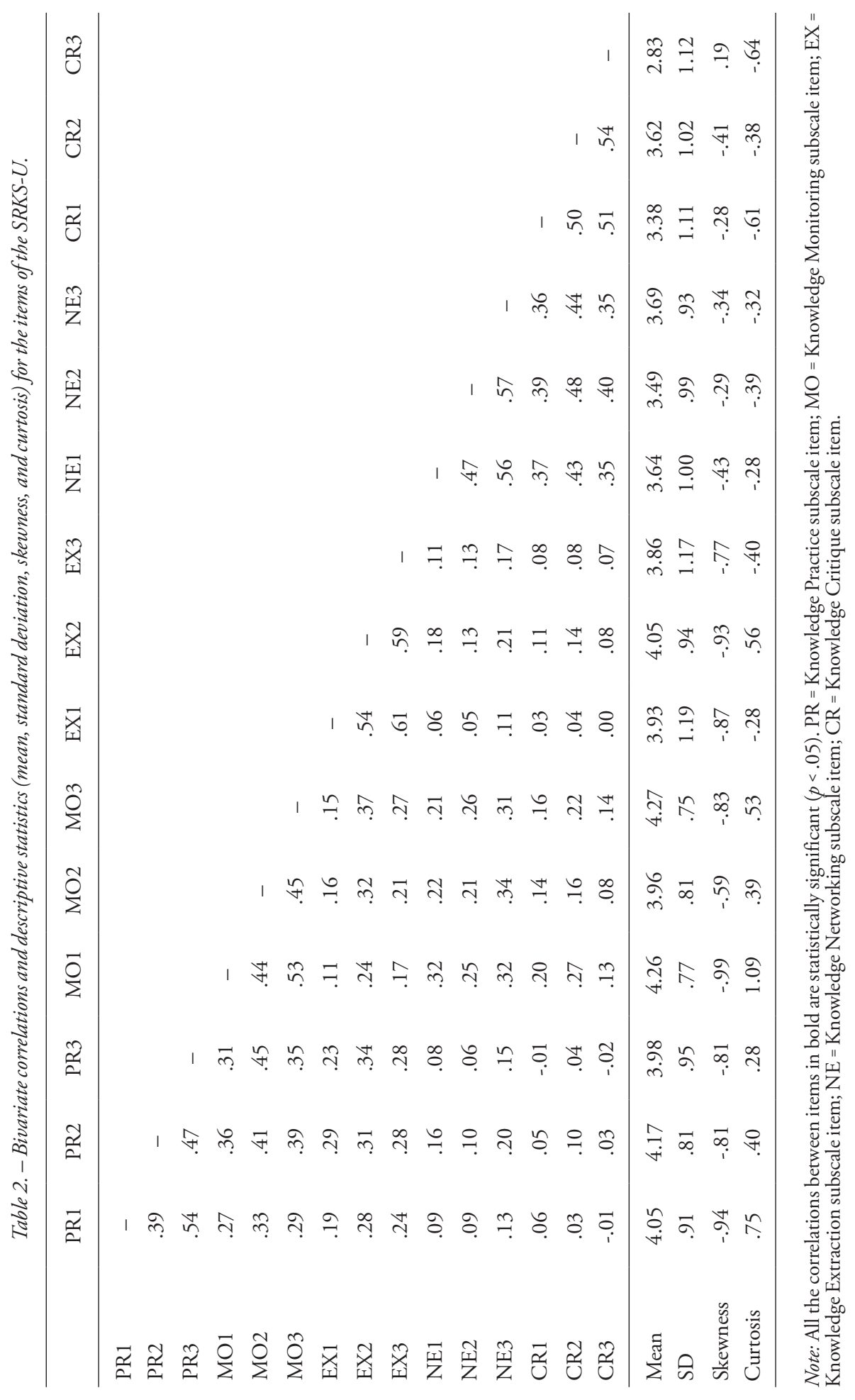


Fit indices

$\mathrm{X}_{(80)}^{2}=543,11(\mathrm{p}<.001)$

$\mathrm{CFI}=.95$

RMSEA $=.05($ CI $90 \%=.05-.06)$

$\mathrm{SRMR}=.04$
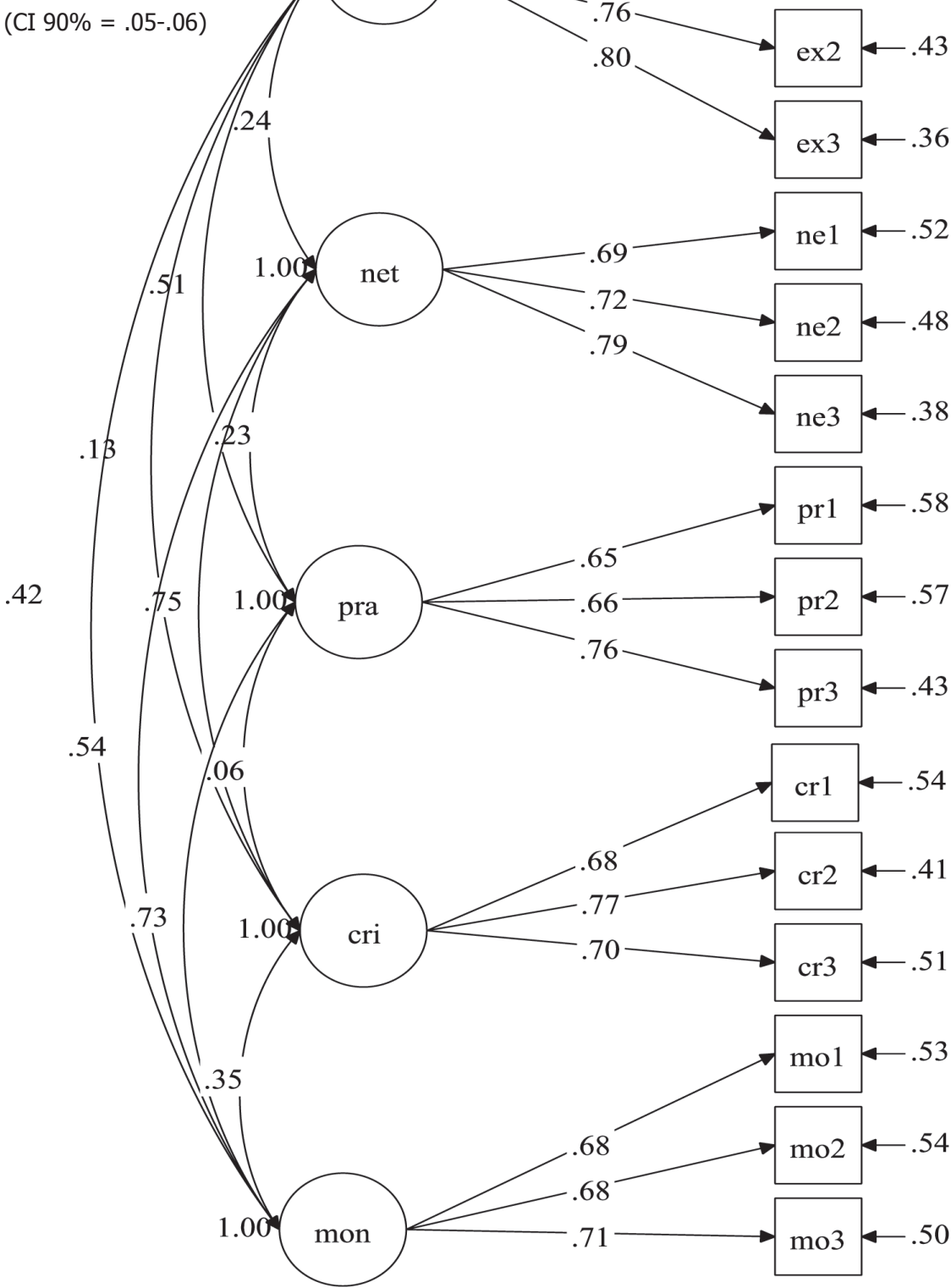

Figure 1. - Confirmatory Factor Analysis results for the measurement model of the SRKS-U. All the parameter estimates are standardized and statistically significant ( $p<.001$; only the correlation between the Knowledge practice and Knowledge critique factors is not statistically significant, $p=.054)$. Ext $=$ Knowledge Extraction factor; Net $=$ Knowledge Networking factor; Pra = Knowledge Practice factor; Cri = Knowledge Critique factor; Mon = Knowledge Monitoring factor. 
The results of the preliminary EFA showed that the solution with five correlated factors explained $53.85 \%$ of the variance and yielded a simple structure for all the items.

In the following stage of the analysis, a Confirmatory Factor Analysis (CFA) was performed in order to test the measurement model for the SRKS-U. The results of the CFA are presented in Figure 1, which shows the fit indices and the standardized parameter estimates for the measurement model.

Except for the chi-square test (probably affected by the large size of the sample used in the present study) all the fit indices (Figure 1) indicated a good fit of the model with the empirical data (Hu \& Bentler, 1999; Schreiber et al., 2006). All the factor loadings were statistically significant $(p<.001)$ and above .60. The 5 factors were significantly correlated with each other $(p<.001)$ with the exception of Knowledge practice and Knowledge critique factors $(p=.054)$. Table 3 sums up the correlations between the five factors in the model.

The alternative measurement models showed a poor fit with the data. The fit indices of the single factor model were as follows: $\chi^{2}(90)=4958.381$, $p<.001$; CFI $=.44$; RMSEA $=.16$; SRMR $=.133$. The fit indices of the higher order factor model were as follows: $\chi^{2}(85)=1248.22, p<.001$; CFI $=$ .87 ; RMSEA $=.08$; SRMR $=.09$. On the basis of these results the five factors model was retained. On the whole the results of the CFAs suggest that the measurement model hypothesized for the SRKS-U was empirically supported by the data.

Table 4 shows the results of the second stage of analysis in which the internal consistency of each subscale was assessed via Cronbach's alpha. All the subscales showed good/acceptable internal consistency.

Table 3. - Correlations between the five factors of the SRKS-U.

\begin{tabular}{lccccc}
\hline \multicolumn{1}{c}{ Subscales } & K. Practice & K. Monitoring & K. Extraction & K. Networking & K. Critique \\
\hline K. Practice & 1 & & & & \\
K. Monitoring & .73 & 1 & & & \\
K. Extraction & .51 & .43 & 1 & 1 & \\
K. Networking & .23 & .54 & .24 & .75 & 1 \\
K. Critique & .06 & .35 & .13 & \\
\hline
\end{tabular}

Note: All the correlations in bold are statistically significant $(p<.001)$. 
Table 4. - Internal consistency of each subscale of the SRKS-U.

\begin{tabular}{lc}
\hline \multicolumn{1}{c}{ Subscales } & Cronbach's alpha \\
\hline K. Practice & .73 \\
K. Monitoring & .73 \\
K. Extraction & .80 \\
K. Networking & .77 \\
K. Critique & .76 \\
\hline
\end{tabular}

Table 5. - Values of the fit indices, $\chi^{2}$ and CFI difference tests for hypotheses about measurement invariance of the SRKS-U across gender.

\begin{tabular}{lccccccccc}
\hline $\begin{array}{l}\text { Invariance } \\
\text { hypothesis }\end{array}$ & $\chi^{2}$ & $\mathrm{df}$ & CFI & RMSEA & SRMR & $\begin{array}{c}\text { Model } \\
\text { comparison }\end{array}$ & $\Delta \chi^{2}$ & $\Delta \mathrm{df}$ & $\Delta \mathrm{CFI}$ \\
\hline $\begin{array}{l}\text { 1-Configural } \\
\text { invariance }\end{array}$ & $679.65^{*}$ & 160 & .94 & .05 & .04 & - & - & - & \\
$\begin{array}{l}\text { 2-Metric } \\
\text { invariance }\end{array}$ & $692.51^{*}$ & 170 & .94 & .05 & .04 & 1 vs 2 & $12.05^{\mathrm{ns}}$ & 10 & 0 \\
$\begin{array}{l}\text { 3-Scalar } \\
\text { invariance }\end{array}$ & $708.31^{*}$ & 180 & .94 & .05 & .05 & 2 vs 3 & $11.78^{\mathrm{ns}}$ & 10 & .001 \\
\hline
\end{tabular}

Note: (a) The structure of the model was constrained to be the same across groups, but the parameters were freely estimated. (b) All of the factor loadings were constrained to be equal across groups. (c) Both the factor loadings and the intercepts were constrained to be equal across groups. ${ }^{\text {ns }}=$ not statistically significant $(p>.05) .{ }^{*} p<.01$.

In order to examine the measurement invariance across gender of the SRKS-U, a hierarchical series of multi-group CFAs was carried out in the third stage of analysis, imposing increasingly restrictive equality constraints on the model's parameters. Table 5 summarizes the results of this analysis, with the fit statistics for the different types of hypotheses regarding measurement invariance across gender.

Configural invariance was tested by specifying Model 1 , in which the structure was constrained to be the same across gender, but the parameters were freely estimated. This model was found to fit the data reasonably well (Table 5), showing indices that were very close to those of the general model tested above. In order to test the hypothesis of metric invariance, a model was specified (Model 2) in which all of the factor loadings were constrained to be equal across gender and compared to Model 1. The comparison of Model 2 
with Model 1 (Table 5) showed that the difference in the chi-square test was not statistically significant and that the CFI was unchanged, indicating that the factor loadings were invariant between female and male students. Model 2 showed also values of the RMSEA and SRMR fit indices that were essentially unchanged from those of the configural model. On the whole these results confirmed the hypothesis of metric invariance of the SRKS-U across gender. In the final step of the analysis, scalar invariance was tested by specifying Model 3, which imposed additional equality constraints to the intercepts of all the items of the scale, and by comparing this model with Model 2. The comparison of Model 3 with Model 2 showed that the chi-square difference test was not statistically significant and that the change in the CFI values was smaller that the cut-off criterion $(\triangle \mathrm{CFI}=.001)$. The other fit indices (RMSEA and SRMR) of Model 3 were practically unchanged from those of Model 2. Therefore, the hypothesis of scalar invariance of the SRKS-U was confirmed.

\section{Discussion}

The purpose of the present study was to develop a short scale with sound psychometric properties in order to measure self-regulated knowledge in university students. The SRKS-U was designed on the basis of the SRL theoretical framework (Pintrich, 2004) and the results of previous studies investigating students' cognitive self-regulation, and it consisted of five subscales each measuring one cognitive process: knowledge extraction, knowledge networking, knowledge practice, knowledge critique, and knowledge monitoring.

On the whole, the results of the data analysis showed that the SRKS-U had good psychometric properties. The CFA empirically confirmed the fivefactor measurement model that was hypothesized for the scale and that all the items proved to have a good fit with the data. In addition, this analysis revealed a pattern of relationships between the factors that was consistent with the SRL theoretical framework (Pintrich, 2004) and the results of previous studies (Credé \& Phillips, 2011). According to the SRL model, students use the knowledge monitoring strategy in order to control the status of their learning process and to regulate the use of the various cognitive strategies as a consequence. Consistently with this theory, in our findings the knowledge monitoring factor proved be positively correlated with all the other factors representing different cognitive strategies. The relationship was especially strong with the knowledge practice strategy, which requires a more regular checking of learning results compared to the the other strategies. The strat- 
egies of knowledge critique and knowledge practice have been sometimes seen as opposing approaches to the learning process (e.g., Tait, Entwistle, \& McCune, 1998) and in fact they were the only two strategies that were not significantly correlated in our findings.

The results of the present study also confirmed the good level of reliability of the SRKS-U. The five subscales showed values of Cronbach's alpha that indicate levels of internal consistency ranging from acceptable to good. Finally, the results of the multigroup analysis confirmed the measurement invariance of the SRKS-U at the configural, metric and scalar levels. The metric invariance results indicate that the structure of the SRKS-U remains consistent across gender and that the contribution of the items towards determining the construct of self-regulation of knowledge does not vary across gender, thus confirming the equivalence of the unit of measurement for male as well female students. The scalar invariance results also indicate the equivalence of the scale's origin across gender, thus confirming that the SRKS-U can be reliably used to compare the scores obtained by female and male students. Therefore, the SRKS-U can adequately account for differences between these two groups as regards their self-regulation of knowledge.

Despite all the strengths of the SRKS-U, some limitations of the present study should be mentioned. Although our data came from a large sample of university students, only Italian students were considered. Future research should therefore be conducted in order to generalize our findings across various other nations and cultural contexts. In addition, some further aspects of the validity of the SRKS-U still need to be verified. For example, the criterion validity could be examined by verifying whether this instrument can predict students' academic results and by investigating the relationships between this instrument and the various other measures developed for the assessment of self-regulation of learning and cognitive strategies.

In conclusion, the SRKS-U has several advantages. It is a reliable instrument with good psychometric properties, by means of which researchers can examine the self-regulation of knowledge in university students. As a consequence, it can be usefully employed in studies that aim to gain a better understanding of this process and its relationship with students motivation, academic achievement and success. Since the SRKS-U adequately accounts for gender differences it can be used to investigate their relevance to the selfregulation of knowledge. This is especially important because research has not yet provided clear indications about this issue (Dowson \& McInerney, 2004). Finally, given its brevity and the clarity of its structure, the SRKS-U can be usefully included in evaluation programs as a screening instrument to provide information that can be used for developing targeted interventions in order to enhance students' self-regulation of learning. 


\section{APPENDIX *}

\section{Scala di Auto-Regolazione degli Apprendimenti - Università (SARA-U)}

(S. Manganelli - F. Alivernini - L. Mallia - V. Biasi, 2015)

Quando studi, quanto frequentemente fai le seguenti cose?

Ricorda: non esistono risposte giuste o sbagliate, ma solo risposte che descrivono meglio o peggio il tuo metodo personale di studio e la tua situazione.

- Faccio dei riassunti delle cose più importanti.

- Cerco delle somiglianze o delle differenze fra quello che sto studiando e quello che già so.

- Mi ripeto più volte le cose importanti da imparare.

- Mi chiedo se sono d'accordo con quello che leggo nei libri o con quello che viene detto a lezione.

- Controllo se ho capito bene quello che sto leggendo.

- Mi scrivo i concetti più importanti di un particolare argomento che studio.

- Cerco dei collegamenti fra le diverse materie che studio.

- Mi rivedo più volte un argomento se voglio impararlo bene.

- Provo a farmi una mia personale idea sulle cose che studio.

- Controllo quale parte di un argomento da studiare non so ancora bene.

- Faccio degli schemi o delle mappe degli argomenti più importanti.

- Cerco di vedere come si collega quello che sto studiando con quello che già so.

- Mi ripeto spesso i concetti più importanti per memorizzarli meglio.

- Provo a "fare delle critiche» o a mettere in discussione quello che trovo sui libri.

* Il presente materiale può essere scaricato, stampato e utilizzato solo per uso personale e non commerciale: pertanto nessuna parte potrà essere copiata, modificata o rivenduta per fini di lucro o per trarne qualsivoglia utilità. L'utilizzo del materiale e di dati e/o risultati da esso derivati può avvenire previa citazione degli autori e dell'articolo di riferimento, secondo quanto di seguito riportato: Manganelli, S., Alivernini, F., Mallia, L., \& Biasi, V. (2015). «The Development and Psychometric Properties of the Self-Regulated Knowledge Scale - University (SRKS-U)». Educational, Cultural and Psychological Studies, 12, 235-254. 


\section{REFERENCES}

Alivernini, F., \& Lucidi, F. (2011). Relationship between social context, self-efficacy, motivation, academic achievement, and intention to drop out of high school: A longitudinal study. The Journal of Educational Research, 104(4), 241-252.

Alivernini, F., Lucidi, F., \& Manganelli, S. (2012). The validation of a scale measuring teaching styles in the Italian context. Procedia - Social and Behavioral Sciences, 46, 1487-1490.

Alivernini, F., \& Manganelli, S. (2015). Country, school and students factors associated with extreme levels of science literacy across 25 countries. International Journal of Science Education, 37(12), 1992-2012.

Barbaranelli, C., \& Natali, E. (2005). I test psicologici: teorie e modelli psicometrici. Roma: Carocci.

Bentler, P. M. (1990). Comparative fit indices in structural equation models. Psychological Bulletin, 107, 238-246.

Biasi, V., Domenici, G., Capobianco, R., Patrizi, N. (2014). Teacher Self-Efficacy Scale: Adaptation and validation in Italy. Journal of Educational Cultural and Psychological Studies, 10, 485-509.

Biggs, J. B., Kember, D., \& Leung, D. Y. P. (2001). The Revised Two Factor Study Process Questionnaire: R-SPQ-2F. British Journal of Educational Psychology, 71, 133-149.

Cera, R., Mancini, M., \& Antonietti, A. (2013). Relationship between metacognition, self-efficacy and self-regulation in learning. Journal of Educational Cultural and Psychological Studies, 7, 115-141.

Cheung, G. W., \& Rensvold, R. B. (2002). Evaluating goodness-of-fit indexes for testing measurement invariance. Structural Equation Modeling: A Multidisciplinary Journal, 9(2), 233-255

Cornoldi, C. (1995). Metacognizione e apprendimento. Bologna: il Mulino.

Credé, M., \& Phillips, L. A. (2011). A meta-analytic review of the Motivated Strategies for Learning Questionnaire. Learning and Individual Differences, 21, 337-346.

De Marco, B., \& Albanese, O. (2009). Le competenze autoregolative dell'attività di studio in comunità virtuali. QWERTY, 4(2), 123-139.

Diseth, A., Pallesen, S., Brunborg, G. S., \& Larsen, S. (2010). Academic achievement among first semester undergraduate psychology students: The role of course experience, effort, motives and learning strategies. Higher Education, 59(3), 335-352.

Dowson, M., \& McInerney, D. M. (2004). The development and validation of the goal orientation and learning strategy survey (GOAL-S). Educational and Psychological Measurement, 64(2), 290-310.

Entwistle, N., \& McCune, V. (2004). The conceptual bases of study strategy inventories. Educational Psychology Review, 16(4), 325-345.

Heikkila, A., Niemivirta, M., Nieminen J., \& Lonka, K. (2011). Interrelations among university students' approaches to learning, regulation of learning, 
and cognitive and attributional strategies: A person oriented approach. Higher Education, 61, 513-529.

Hofer, B. K., \& Shirley, L. Y. (2003). Theaching self-regulated learning through a "learning to learn» cours. Teaching of Psychology, 30(1), 30-33.

Hu, L. T., \& Bentler, P. M. (1999). Cut-off criteria for fit indices in covariance structure analysis: Conventional criteria versus new alternatives. Structural Equation Modeling, 6, 1-55.

Joreskog, K. G., \& Sorbom, D. (1993). LISREL 8: User's guide. Chicago: Scientific Software.

La Rocca, C., Margottini, M., \& Capobianco, R. (2014). Ambienti digitali per lo sviluppo delle competenze trasversali nella didattica universitaria. Journal of Educational Cultural and Psychological Studies, 10, 245-283.

Muthén, L. K., \& Muthén, B. O. (1998-2012). Mplus user's guide (7th ed.). Los Angeles, CA: Muthén \& Muthén

Pellerey, M. (1996). Questionario sulle strategie di studio. Roma: LAS - Libreria Ateneo Salesiano.

Pintrich, P. R. (2000). The role of goal orientation in self-regulated learning. In M. Boekaerts, P. R. Pintrich, \& M. and Zeidner (Eds.), Handbook of selfregulation (pp. 451-502). San Diego, CA: Academic Press.

Pintrich, P. R. (2004). A conceptual Framework for assessing motivation and self-regulated learning in college students. Educational Psychology Review, 16(4), 385-407.

Pintrich, P. R., \& V. De Groot, E. (1990). Motivational and self-regulated learning components of classroom academic performance. Journal of Educational Psychology, 82(1), 33-40.

Pintrich, P. R., Smith, D., Garcia, T., \& McKeachie, W. (1991). A manual for the use of the Motivated Strategies for Learning Questionnaire (MSLQ). The University of Michigan, Ann Arbor, MI.

Richardson, M., Abraham, C., \& Bond, R. (2012). Psychological correlates of university students' academic performance: A systematic review and metaanalysis. Psychological Bulletin, 138(2), 353-387.

Schreiber, J. B., Nora, A., Stage, F. K., Barlow, E. A., \& King, J. (2006). Reporting structural equation modeling and confirmatory factor analysis results: A review. Journal of Educational Research, 99, 323-337.

Sizoo, S., Malhotra, N., \& Bearson, J. (2003). A gender-based comparison of the learning strategies of adult business students. College Student Journal, 37(1), 103-110.

Socha, A., \& Sigler, E. A. (2014). Exploring and «reconciling» the factor structure for the Revised Two-factor Study Process Questionnaire. Learning and Individual Differences, 31, 43-50.

Steiger, J. H. (1990). Structural model evaluation and modification: An interval estimation approach. Multivariate Behavioral Research, 25, 173-180.

Tait, H., Entwistle, N. J., \& McCune, V. (1998). ASSIST: A reconceptualisation of the approaches to studying inventory. In C. Rust (Ed.), Improving student 
learning: Improving students as learners. Oxford: Oxford Centre for Staff and Learning Development.

Vandenberg, R. J., \& Lance, C. E. (2000). A review and synthesis of the measurement invariance literature: Suggestions, practices, and recommendations for organizational research. Organizational Research Methods, 3(4), 4-70.

Van de Schoot, R., Lugtig, P., \& Hox, J. (2012). A checklist for testing measurement invariance. European Journal of Developmental Psychology, 9(4), 486-492.

Vermunt, J. D. (1998). The regulation of constructive learning processes. British Journal of Educational Psychology, 68, 149-171.

Weinstein, C. E., \& Palmer, D. R. (2002). Learning and study strategies inventory user manual. H\&H Publishing Company, Inc.

\section{RiassunTO}

L'autoregolazione della conoscenza fa riferimento ai processi mentali e alle competenze utilizzate dagli studenti per adattare e modificare le loro conoscenze e che possono condurre a risultati positivi in termini di apprendimento. Nel presente lavoro viene proposta una scala per la misurazione dell'autoregolazione delle competenze legate all'apprendimento in studenti universitari. La scala è stata costruita sulla base del framework teorico dell'apprendimento autoregolato (Pintrich, 2004), che ha ricevuto un forte sostegno empirico nella letteratura scientifica. La "Self-Regulated Knowledge Scale - University» (SRKS-U) è composta da 5 sottoscale, che misurano le seguenti strategie cognitive: estrazione della conoscenza, collegamento della conoscenza, allenamento della conoscenza, critica della conoscenza e monitoraggio della conoscenza. Nel complesso le analisi illustrate nel presente contributo forniscono evidenze empiriche circa le buone proprietà psicometriche della $S R K S-U$, confermando la validità e l'attendibilità della scala, e la sua affidabilità come strumento per confrontare studenti e studentesse nell'autoregolazione dell'apprendimento. Considerando le caratteristiche illustrate nel presente contributo, la SRKS-U costituisce uno strumento di misura pratico e affidabile, che può essere proficuamente impiegato sia in contesti di ricerca sia come strumento di screening in programmi di valutazione per ottenere informazioni utili a orientare interventi volti al miglioramento dell'autoregolazione dell'apprendimento negli studenti.

Parole chiave: Auto-regolazione dell'apprendimento, Competenze chiave, Imparare ad apprendere, Strategie cognitive, Validità.

How to cite this Paper: Manganelli, S., Alivernini, F., Mallia, L., \& Biasi, V. (2015). The development and psychometric properties of the «Self-Regulated Knowledge Scale - University» (SRKS-U) [Sviluppo e proprietà psicometriche della «Scala di Auto-Regolazione degli Apprendimenti - Università» (SARA-U)]. Journal of Educational, Cultural and Psychological Studies, 12, 235-254. doi: 10.7358/ecps-2015-012-mang 